HF Have you any comments on individuals in the mental health field - I suppose we should avoid those still living.

GG I've mentioned T. P. Rees; he was the person I think who really made an early impression on me. There was Jack Rees, and Ronald Hargreaves, who had been with WHO. I have mentioned Walter Maclay - I think he gets less credit than he ought to have - he was a very important and benign influence behind the scenes. Macmillan I knew well, of course, from when I was in Nottingham in the early part of the War; again, a man for whom I had a very high regard. And of course there was Aubrey Lewis, with all his intellectual qualities, but I suppose amongst the psychiatrists of whom I have the pleasantest recollections is Denis Hill who set up, after all, the first department in a London teaching hospital, and breaking into them was no easy matter. His was the first London Chair, but he had predecessors outside London, of whom I knew best Bill Trethowan. Then I have mentioned that group of whom you were one-Poole and others in the Manchester Region, who I've always looked on as pioneers who haven't had enough recognition. There was Tredgold at UCH, who was the Regional Psychiatrist for the South East Metropolitan Region - a very nice man.

HF Yes. I succeeded him as Editor of Mental Health, which was the NAMH's journal.

GG Another person who perhaps ought to have a little credit and doesn't get it is Sir Alan Daley, who was the County Medical Officer of London. As I said, he was the first Chairman of the Standing Mental Health Advisory Committee, and an interesting chap. He was able to take on board some of the needs of psychiatry and hold the balance between the warring elements in that Advisory Committee. They were warring, I can tell you, so I think he ought to be in the 'gallery'.

\title{
Physician liability for treating mentally incompetent patients
}

\section{The views of one American lawyer}

\section{Allan B. Morrison*}

The issue of the rights and obligations of those involved in doing research on patients who are incapable of giving their consent to treatment is a difficult one. This difficulty is reflected in the papers and discussion which form the basis of the book Consent and the Incompetent Patient: Ethics, Law and Medicine (eds. S. R. Hirsch \& J. Harris) ${ }^{1}$ and that were the subject of the conference that led to it. Had I been in attendance, I am sure that I would have gained insights not available from the printed version on which I have had to rely. Nonetheless, I have sufficient sense of the proceedings to see where there are

* Mr Morrison is a practising lawyer in the United States. He is the director of the Public Citizen Litigation Group, a public interest law firm which he co-founded with Ralph Nader in 1972. He also lectures at both Harvard and Columbia Law Schools. areas that an American view, or at least the views of one American lawyer, might be of interest.

There are two important caveats for the reader. First, a reminder about American law. Under our system, there is not one answer to most questions of law, especially those having to do with issues of negligence or battery, because the law in those areas is established by each of the 50 states, rather than by the federal government. Thus, while there are many issues on which the states are quite close, there are others on which there are several different views which make it impossible to give an 'American' answer to a legal question. And given the novelty of this question, there is clearly no single American answer, in part because most states have yet to address the issue at all.

Second, although I have been practising law for more than 20 years, the subject of this book is 
not my area of expertise. Nor do I claim to have studied the law in this area before writing this essay. I do a substantial amount of litigation, and I work in public policy areas of the law, but these views should be taken as no more than those of a single lawyer thinking about how the American legal system might handle these problems; with, it is hoped, the maximum sensitivity to all the interests at stake.

At the outset, it is essential to define our task by pointing out both what is under discussion and what is not. I am not offering an American view of how a court might respond when a seriously ill or injured adult is incapable of rendering consent for treatment that is intended to improve his physical or mental health. Much of the discussion of the laws of battery and negligence, including the doctrine of informed consent, seems directed to that topic. In particular, the discussion by Henry Brooke, QC, about American law and its alleged rigidity, seems to me to be directed at that topic. What this essay will discuss is the very different issue of what Professor Hirsch describes as "non-therapeutic research when the patient takes the risk but others are the ones most likely to benefit." (p 3). Such research might involve taking a blood sample from a mentally incompetent person, who is otherwise healthy, or taking a sample of chromosomes from a chronic mentally ill individual, in order to test a theory about whether something in the blood or chromosomes is the cause of those conditions. Since there is always the possibility of problems arising or questions being raised about even routine procedures, the issue is: what would American law say about the legality of conducting such non-therapeutic research on patients who are mentally incapable of giving consent, however that term is defined.

Personal liability for such research on the mentally incompetent raises two separate questions for the physician. The basic problem arises because the patient is mentally incapable of providing the informed consent required, although I would suppose that similar problems would arise in the case of a physical incapacity, such as a coma, that also made consent impossible. In such situations, one question the physician might ask is, "can I go to jail or lose my licence" for giving drugs to an individual who is unable to consent, when one of the purposes of the treatment is to test the efficacy, and perhaps the safety, of the medication? Second, "if the patient is harmed as a result of the treatment, can I be made to pay for future medical expenses as well as other damages," which in the United States would include loss of earnings, pain and suffering, etc? While it would be nice to be able to obtain an answer to the question of the legality of such research before undertaking it, the American legal system is set up in a way that an advisory opinion is very difficult to obtain and would not provide any protection if the injured person later sued the doctor.

Since the problem is created because of the incapacity of the patient to consent, the issues of criminal liability for battery, or loss of licence for committing that offence, should be able to be avoided quite readily if the legislature and/or the licensing authorities permit such treatment and provide specific procedures which must be employed and which are in fact followed in the particular case. On this, I feel quite confident, since it is the state that creates the criminal law and the licensure law, and the state can insulate an individual from what otherwise might be a violation of those laws by creating exceptions to them. Of course, the questions of when and under what conditions such experimentation should be allowed, and what body should decide on those conditions, are far from easy, but assuming that the rules have been satisfied, the question of whether a physician should be held criminally responsible for having followed those laws is not a difficult one. Even in the absence of a change in the criminal law, it would be a rare prosecutor indeed who would bring charges against a physician for having complied with the medical society's rules on research even though the physician's conduct might constitute the technical offense of battery under the criminal statutes. The same would also be true if a patient filed disciplinary charges with the physician licensing authority, or, if situated in England and Wales, made a complaint to the General Medical Council.

The issue of the physician's responsibility to the individual who is injured as a result of the treatment/ experimentation presents a different question. The first possibility would be to have the legislature insulate the physician from civil liability the same way that it did for criminal and licensure liability. In the United States at least, there might arise the constitutional question of whether the legislature is treating different kinds of batteries differently, and thereby violating the guarantees of equal protection of the laws to all individuals. My suspicion is that the courts would not look favourably on such an equal protection claim, because there is no reason to suspect that the legislature would be singling out mentally incompetent patients for any discriminatory treatment. Therefore, such a law would probably be upheld on the ground that the distinctions between the kinds of patients who are entitled to recover, and those who are not, is at least rational if not perfect in the lines that are drawn.

In the absence of legislation, the problem becomes more complex. By way of background, it should be recognised that even now, the law of consent is not an absolute requirement, since patients who are unconscious or otherwise unable to give consent are routinely treated in emergency or quasi-emergency situations in order to save their lives. On the other 
hand, the difference here is that this is not treatment to prevent death or serious deterioration in health, but pure research and hence that justification cannot be offered.

But even in the absence of life-threatening conditions, consent, while it is supposed to be informed, is often less than ideally based on adequate knowledge of all the circumstances, and even then the standard of unconsented-to battery, which produces absolute liability without regard to reasonableness, is often not followed. In such situations, the patient is not entirely without recourse since the physician must have acted reasonably under the circumstances, a test that would probably be met if the physician followed the protocol of the hospital or medical society for handling such situations. At the very least, the physician would have to live up to any standards of reasonableness in conducting the research.

Beyond that, it is difficult to say how the matter would be resolved. A court would almost certainly look to see whether there was any guardian, parent, spouse, or other relative who was consulted and given the opportunity to consent, and either did so or said that they would not because they did not wish to assume any personal responsibility for having done so. In addition, a court would almost surely look to the reasonableness of the conduct and the fairness of any prescribed procedures in determining not only whether the physician acted reasonably, but whether an exception to the consent doctrine should be created, similar to that for emergency treatment.

Going in the opposite direction, at least under the laws of the United States, would be the recognition that if no liability is found, the incompetent patient (or his family) will be required to pay for medical treatment for as long as the unintended consequences of the unconsented-to treatment persist. In addition, there may also be substantial damages for loss of income, pain and suffering, and other kinds of injuries for which the American law provides recovery. To the extent that it could be proven as a fact that the incompetent would never have been able to earn a living or otherwise engage in a useful life without the treatment, that would be a defence against that part of the claim for damages, but not as to the claim for the medical expenses. However, in many cases the largest element of damages - the cost of medical care - would create a very different set of dynamics in the United States where there is no national health insurance, than in the United Kingdom where there is.

One aspect of American law makes it less than likely that these issues will be tested in the courts anytime soon. Injured patients can sue only if they can show that their injuries were due to the conduct of the physician, and that kind of proof may be very difficult to establish in these kinds of cases. That is especially so where the experiment does not cause additional harm to the patient, but simply does not improve his condition. Lack of success is never a basis for recovery in American courts in circumstances such as this, and the courts would award only nominal damages for even an unconsented-to battery that produced no new harm when done for proper motives such as research. Because of these difficulties of proof and the small likelihood of recovering damages, it is quite likely that no American case will present these issues in the near future.

But if such a situation does arise, it is impossible to predict with any degree of certainty how a case involving non-negligent treatment through the use of experimental medication on a mentally incompetent patient would be decided if the treatment produced ill effects and the patient sued the physician. That uncertainty is created because the case would have to be decided according to principles of the common law which are not easy to apply in this situation, and because they will be applied after the fact rather than being known to everyone in advance. Thus, while the answer to the question of physician liability is difficult enough in itself, its difficulty is compounded when it has to be answered in the face of a seriously injured human being, whose rights must then be balanced against the interests of society in improving medical treatment and the interest of the physician in avoiding responsibility for having done no more than commit a technical battery, while otherwise acting reasonably under the circumstances. In short, it is a question whose answer cries out for a legislative solution in the United States before the case arises in the courts of law.

Finally, let me say a word about the likelihood of success for alternatives to legislation, in particular efforts by the professions to deal with the issues themselves. As I've mentioned above, some such efforts, at least in the licensing and criminal law areas, may be effective. But when the issue is injury to another person, then under American law the professions do not have the final say - that belongs to the courts and legislatures because the results affect not only the professionals, but those that they trust. Therefore, nothing that the professions could do alone, even in consultation with other interested groups, could produce a definite answer.

\section{Editorial note}

1 Consent and the Incompetent Patient: Ethics, Law and Medicine edited by Steven R. Hirsch and John Harris, 1988, pp 111, is available from the Editorial Office, Royal College of Psychiatrists, 17 Belgrave Square, London SW1X 8PG, price f7.50. Cheques should be made payable to the Royal College of Psychiatrists. Postage and packing: UK and overseas surface free. Airmail $£ 4.00$ per book. 